\section{SHOULD ALL CPD BE} VERIFIABLE?

The General Dental Council (GDC) has launched a consultation on new statutory rules for continuing professional development (CPD).

$\mathrm{CPD}$ is a legal requirement for all registered dental professionals. The GDC is proposing to change the rules which govern CPD requirements for registrants.

Among the key changes being proposed are:

- New minimum CPD hours requirements

- The introduction of high level learning outcomes that relate to the Standards for the dental team

- Embedding planning and reflection into CPD requirements

- Emphasising the importance of good quality CPD by requiring that all $\mathrm{CPD}$ is verifiable

- Introducing annual CPD declarations as a requirement of ongoing registration.

The new rules, which are set out in proposed new legislation, seek to embed CPD as a regular part of registrants' professional life. They also aim to support registrants to meet the GDC's Standards for the dental team and provide the GDC with regular assurance that registrants are keeping up to date.

The consultation is now open and the GDC is keen to hear views from registrants and the wider dental sector, including those involved in delivering and supporting CPD in dentistry.

The consultation is open until 21 March 2014. To contribute visit: www.gdc-uk.org/ CPDconsultation.

The GDC has also developed an interactive site with case studies, scenarios and FAQs to support the new Standards for the dental team by testing registrants' knowledge. Learning materials for each of the nine principles are included. www.gdc-uk.org/ Dentalprofessionals/Standards/ cases/Pages/default.aspx

A DENTIST'S LIFE

$\mathrm{T}$ The time I get up very much depends on which of my children decide they want to climb into my bed for a snuggle (if not both of them!) which can be as early as 5 am - but usually I am up around 6 am most mornings. The first thing that I do is brush my teeth - I have to do that before anything else - and the next task is to get Ishani up for school on weekdays, or dance class on a Saturday. Then the day starts!

I cannot start my day without a bowl of porridge. I like Quaker Oats with golden syrup, skimmed milk and blueberries or banana on top. My husband, Hiren, has that ready for me as soon as I make it downstairs after getting the children ready.

I travel to the practice by car - nothing fancy, I have a little Peugeot 107 that does the job and is easy to park in our limited parking spaces at the practice. My previous car was a monster - a Land Rover Discovery. I drop off Ishani at school on the way, or Shreyan at pre-school; Hiren and I take it in turns to drop each child off.

Up until recently my family and I lived in the house next door to the practice. We did this for about two years, and it was the best commute ever. The decision to live next door was driven by Shreyan's birth, and the fact that as a working mum with two young children (Ishani was just four when I bought the practice), being next door meant that I could combine mummy duties with giving the practice the time it needed as a new business. Although the practice has been established for over 25 years, I was new to it and it was new to me.

Late last year we moved out of the house next to the practice and back to my hometown of Milton Keynes, which is about 20 minutes away. It gives me the distance I need to separate work and family life again. I have predominantly been able to make this move as I have

\section{LOVING EVERY MINUTE}

Debbie Ganguli is Principal Dentist and Clinical Director at Cherry Trees Dental in Leighton Buzzard. In 2013 the practice won a Private Dentistry Award

for their children's dental health initiative in the best community and charity project category. Debbie is married to IT Project Manager Hiren Patel. They have an eight-year-old daughter, Ishani, and a son, Shreyan, three.

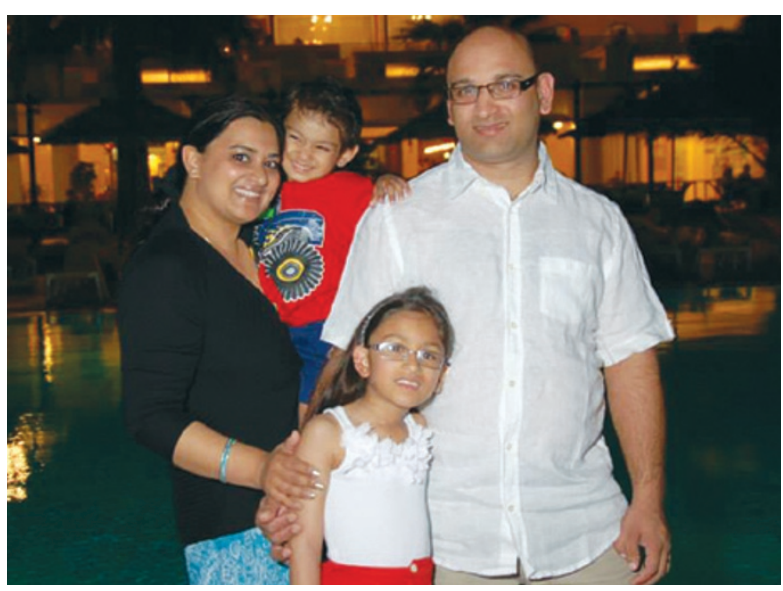

'I would not be able to manage my busy workload and responsibilities were it not for my husband and my lovely mother...'

an excellent, dynamic and very efficient team of eight led by my trainee practice manager, Yvonne Hosking. Yvonne has taken over many of the tasks I used to undertake when I first took on Cherry Trees Dental, so that I can concentrate on what I enjoy the most: patient care and dentistry.

I work full time: currently Monday to Thursday I am with patients all day, with the occasional late evening for sedation cases or implants. At the moment I am taking a year-long certificate in implant placement. I try to spend Fridays with Shreyan; it has been difficult for me to get that time with him in the same way I had with his sister due to the responsibilities of being a practice owner. Friday should be my admin day, but I tend to try to fit admin in during the week when the children are in bed.

After qualifying from Guy's in 2001, I spent the first five years of my career dedicated to special care and paediatric patients. I held senior management posts in the dental departments at Milton Keynes and Vale of Aylesbury PCTs, and was the clinical lead for the dental surgery at the National Spinal Injuries Centre at Stoke Mandeville Hospital. Following Ishani's birth, I decided to return to general practice as an associate at a private 
practice in Leighton Buzzard. I missed the challenge of the management side of dentistry, so when Ishani reached school age, I decided to run my own practice.

Just a few days after the practice purchase completed, I discovered I was pregnant with Shreyan. I was compelled to return to work when Shreyan was just two weeks old, so for the first nine months of his life, he and my mother came to work with me every day.

I love working with children, and some of my time is dedicated to the Cherry Trees Dental Education for Schools Initiative. A team member and I will spend a session at a school or youth group delivering bespoke lessons such as 'The effects of rationing on teeth during WWII' or 'Barber surgeons and dental health in Tudor times'. These are written in line with the National Curriculum and are delivered free of charge.

I would not be able to manage my busy workload and responsibilities were it not for the fantastic support structure at home: my long-suffering husband and my lovely mother, Swati. As an IT Project Manager Hiren rarely has breathing time, but we share the responsibility of getting the children to their various activities: in Ishani's case piano, Brownies, swimming, Kumon and dance, and gymnastics for Shreyan.

Ishani has gained a place at the same dance school that my sister and I attended, learning the South Indian classical dance form Bharatanatyam. This has inspired me to return to classes myself, with my Guruji, who has been teaching me since I was 11 , in the advanced level class. Some of the other students in my class are as young as ten but I am loving every minute!

I usually get home late from the practice, but I'm getting better. Hiren was getting fed up of me turning up at the children's bedtime so he set up remote access to the practice so that I can work from home.

I don't have much time to cook, but I love cooking. I try to be strict with the children's diets, but it's easier said than done. Hiren and I have a notoriously sweet tooth; at one time we had a secret chocolate stash - don't tell the children!

I am Hiren's dentist; he kindly allowed me to do my first ever molar endo on him when we were at university - four canals taking 24 hours of chair time! I also treat mum and Ishani. Shreyan won't sit in the chair!

I usually go to bed by $11 \mathrm{pm}$, but it depends on how tired I am. Sometimes I work late into the night; other times I will have a sleep and wake up during the night to work. I do think about the dayto-day aspects of running the practice before I go to sleep, although less these days on account of my team. I hope my team don't think about dentistry before they go to sleep.

INTERVIEW BY KATE QUINLAN
BOOK REVIEW

PERI-IMPLANT THERAPY FOR THE DENTAL HYGIENIST: CLINICAL GUIDE TO MAINTENANCE AND DISEASE COMPLICATIONS

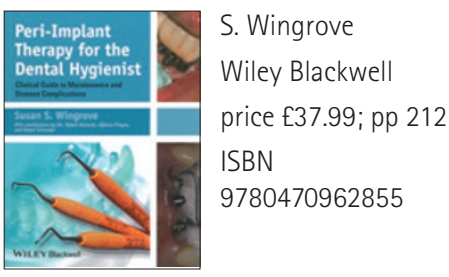

Peri-implant therapy for the dental hygienist states dental implants are ranked second behind bleaching as the most asked about treatment in dentistry. This clearly demonstrates the popularity of dental implants over the last few decades. As such the profession must ensure it is prepared to deal not only with the success of treatment but also the long-term maintenance and potential complications that may arise, a point that is beautifully demonstrated throughout this text.

Wingrove has successfully drawn together a topic that easily confuses and strikes fear into many. The author cleverly divides the book into nine well written and concise chapters, starting with an important look into the history of dental implants. The reader then gains a good insight into many aspects of modern day implant dentistry. These chapters cover very important information that all dental professionals who are exposed to dental implants must be familiar with, including: patient selection, surgical procedures, restorations, complications and maintenance.

A recurring theme within the book is the importance of maintenance and regular monitoring of dental implants, describing a monitoring regime, appropriate instruments and carefully designed restorations. The book gives the reader a good overview of patient selection, covering contraindicating factors and briefly mentions alternative restorations for the edentulous space.

The text is very well written and easily understood proving to be a good introduction to dental implants in general; giving details of implant components was a nice addition. This text is impressively supported by a large selection of images, which beautifully demonstrate points made within the text. The author provides ample references to literature supporting the content of this book.

It is important to realise that in many areas this book merely scratches the surface but once read will provide a good basic knowledge of this important topic. With the increasing prevalence of dental implants, not only would I recommend this book to its intended audience of dental hygienists, but feel it is a good read for all dental professionals and undergraduates who will inevitably come across dental implants at some stage of their career.

W. KEYS

\section{OVER 900 FOUNDATION TRAINING PLACES ALLOCATED}

Nine hundred and seventy dental foundation training places have been allocated for 2014. Of these, 49\% of applicants secured their first choice; $71 \%$ were offered a place on one of their top three schemes; and $88 \%$ of applicants were offered a place on one of their top ten schemes.

There were 1,318 online applications to the 2014 Dental Foundation Training programme, an increase of 12.5\% from 2013. Of these, 1,290 eligible candidates were invited to a selection centre in November, where standard assessments were carried out. All applicants also sat a situational judgment test. So far, $80 \%$ of appointable applicants have been offered places on dental foundation training schemes in England, Northern Ireland and Wales, starting in 2014.

Health Education England Regions (Deaneries) will be allocating the 970 successful applicants to individual training practices. Further training places are expected to become available later in the year; 244 candidates on a reserve list will be notified about these after BDS final examinations. 